\title{
FORMATION OF 3-MONOCHLORO-1,2-PROPANEDIOL FATTY ACID ESTERS DURING DEEP-FAT FRYING OF PRE-FRIED DEEP FROZEN FOOD WITH DIFFERENT SALT CONTENT
}

\author{
E. KePpelné BognÁR*, K. ZAY and L. Somogyi \\ Department of Grain and Industrial Plant Processing, Szent István University, H-1118 Budapest, Villányi út 29-43. \\ Hungary
}

(Received: 15 September 2019; accepted 19 December 2019)

\begin{abstract}
Changes of edible oil quality factors and formation of 3-monochloro-1,2-propanediol fatty acid esters (3-MCPD-FE) during deep-fat frying in four different experiments (control, salt, pork chop, and chicken liver) with high oleic sunflower oil were compared in this study. Based on the results of investigated oil quality parameters, which were free fatty acid (FFA), anisidine value (AV), UV extinction at 232 and $268 \mathrm{~nm}\left(\mathrm{E}_{232}\right.$ and $\mathrm{E}_{268}$, respectively), and total polar material (TPM), only a modest deterioration of the frying oil was observed. As we expected, the 3-MCPD-FE content in the control samples did not reach the limit of quantification $\left(0.1 \mathrm{mg} \mathrm{kg}^{-1}\right)$, while the table salt itself caused a slight increase. The results of pork chop and chicken liver experiments were not statistically different from each other, after the third frying circle 0.52 and $0.39 \mathrm{mg} \mathrm{kg}^{-1} 3$-MCPD-FE levels were reached, respectively. Based on these values, the human exposure estimation resulted in a low risk.
\end{abstract}

Keywords: 3-MCPD, $\mathrm{NaCl}$ content, frying, food matrices, risk assessment

Deep-fat frying is one of the most commonly used food preparation steps in domestic cooking. Due to several factors, including sensory properties, namely taste, golden brown colour, crunchy texture, of the fried food and low cost, simplicity and rapidity of the process, frying is a popular and widely used process among consumers (ZIAIIFAR et al., 2008; OKE et al., 2018). Several complex reactions between the food components, air, and oil take place at the temperature of frying, as high as $150-190^{\circ} \mathrm{C}$ (CHOE \& Min, 2007). Oxidation, hydrolysis, isomerisation, polymerisation, and Maillard reaction result in volatile compounds, hydrolysis products, oxidized triacylglycerol monomers, cyclic compounds, trans configuration compounds, polymers, acrylamide, etc. Because of the fat uptake, these compounds are present in both frying oil and fried food (ZHANG et al., 2012).

Beside these reactions, 3-monochloro-1,2-propanediol fatty acid ester (3-MCPD-FE) formation was reported during frying by previous studies, as well (CALTA et al., 2004; WONG et al., 2017a,b). Free form of these contaminants was classified by International Agency for Research on Cancer (IARC) as possibly carcinogenic to humans - category 2B (IARC, 2013). The temperature of frying fulfils the condition for 3-MCPD-FE formation, which starts at $140{ }^{\circ} \mathrm{C}$ (De Kock et al., 2016). Additionally, chlorine-containing compounds and water are provided by the food fried in the oil, effect of both was proved before (CALTA et al., 2004; ZHOU et al., 2014). 3-MCPD-FE formation was examined exhaustively during deodorization of vegetable oils conducted at high temperature (DestaILlats et al., 2012).

\footnotetext{
* To whom correspondence should be addressed.

E-mail: zsofi.bognar@outlook.hu
} 
However, the examination of 3-MCPD-FE formation is of paramount importance during frying as well.

The objective of the current work was to study the formation of 3-MCPD-FE during frying different pre-fried deep frozen products in high oleic sunflower oil (HOSO). HOSO was chosen due to its high oxidative stability. Beside 3-MCPD-FE concentration some usual parameters, including free fatty acid content, UV extinction, anisidine value, and total polar compounds were investigated. The frying experiments were performed under laboratory conditions.

\section{Materials and methods}

\subsection{Chemicals and solvents}

Diethyl ether, ethanol, ethyl acetate, $n$-hexane, and HPLC-grade water were purchased from VWR (Debrecen, Hungary). Toluene, iso-hexane, sodium bromide, phenylboronic acid (PBA), and potassium hydroxide solution in ethanol were obtained from Merck (Budapest, Hungary). Methanol, sodium hydroxide, and anhydrous sodium sulphate were obtained from Reanal Laborvegyszer (Budapest, Hungary). 1,2-Bis-palmitoyl-3-chloropropanediol-d $\mathrm{d}_{5}$ internal standard was purchased from Chiron AS (Trondheim, Norway). All reagents and chemicals were of analytical grade.

\subsection{Samples}

Refined high oleic sunflower oil (HOSO) was supplied by Bunge Limited (Bunge Zrt. Hungary). Sodium chloride $/ \mathrm{NaCl}$ as table salt, pre-fried, breaded deep frozen pork chop and chicken liver (Nádudvari products) were purchased from the local market.

\subsection{Methods}

1.3.1. Deep-frying procedure. Deep-frying was conducted under laboratory conditions. Two hundred grams of HOSO in a beaker was heated up to $160{ }^{\circ} \mathrm{C}$ on hot plate with magnetic stirring. The temperature was monitored through the whole process with a thermometer. Reaching the target temperature, the pre-fried chop (pork or liver) was added to the oil without thawing, and the magnetic stirring was slowed down or turned off. The frying ratio of the chop: oil was 1:15. The frying time was 5 min according to the recommendation on the packaging of the product. After the frying time has expired, the fried object was removed from the oil, the oil was cooled down to $45-50{ }^{\circ} \mathrm{C}$, and $30 \mathrm{~g}$ oil was taken as the first sample. This process was repeated with the residual oil (170 $\mathrm{g}$ without calculating the oil uptake of fried object) twice more (altogether 3 frying circles were conducted with the different prefried foods). By the salty experiment, $1 \%$ table salt was added to the oil after reaching the target temperature the first time. The control experiment was conducted without adding any object or salt. The salty and control experiments run the same way as the pork and liver experiments: heating up to $160{ }^{\circ} \mathrm{C}$ - keeping at $160{ }^{\circ} \mathrm{C}$ for $5 \mathrm{~min}$ - cooling down to $45-50{ }^{\circ} \mathrm{C}$ - sampling - repeating three times.

1.3.2. Determination of acidity of oils. The acidity of oils was determined according to the ISO 660:1996 standard based on titrimetric principle. The acidity, expressed as percentage of mass, was calculated to oleic acid. 
1.3.3. Determination of ultraviolet absorbance expressed as specific UV extinction of oils. UV extinction at the wavelength 232 and $268 \mathrm{~nm}$ of oils was determined according to the ISO 3656:2002 standard. The absorbances of the samples dissolved in $n$-hexane were measured against pure $n$-hexane, and the results were expressed as the absorbance of a solution of oil at a concentration of $1 \mathrm{~g} / 100 \mathrm{ml}(1 \%)$.

1.3.4. Determination of anisidine value of oils. The anisidine value (AV) of the oils was determined according to the ISO 6885:2016. Anisidine value means one hundred times the increase in absorbance, measured at a wavelength of $350 \mathrm{~nm}$ in a $10 \mathrm{~mm}$ cell, of a test solution when reacted with $p$-anisidine. The AV has no dimensions, and is calculated and quoted on the basis of $1 \mathrm{~g}$ of the test sample in $100 \mathrm{ml}$ of a mixture of solvent and reagent.

1.3.5. Determination of total polar material (TPM). Testo 270 cooking oil tester was used for the determination of total polar material (TPM). The sensor of the tester works on a capacitive basis and determines the TPM as a \% of the cooking oil. This method is popular among restaurateurs because it is simple, robust, and accurate, moreover the measurement can be performed during the frying process. In several countries there is a limit for the total polar compound, it is usually $25 \%$, at which frying oil is no longer suitable for human consumption.

1.3.6. Determination of 3-MCPD-FE content of oils. The concentration of 3-MCPD-FE was determined according to the official AOCS Cd 29b-13 Method (AOCS, 2013). This method is used for determination of 2- and 3-MCPD fatty acid esters and glycidyl fatty acid esters in edible oils and fats (in this study we examined only 3-MCPD-FE). The method is based on alkaline-catalyzed ester cleavage, and derivatisation of free diols with PBA. These derivatives were measured in splitless mode by GC/MS coupled system (Agilent 6890 coupled with 5973). Column type was Ultra Inert DB-35MS (35\% phenyl methyl siloxane 30

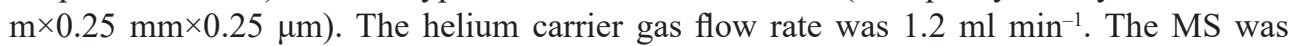
operated in SIM (selected ion monitoring) mode. Deuterated internal standard was used for the determination. Characteristic ions for derivatised 3-MCPD- $\mathrm{d}_{5}$ at $\mathrm{m} / \mathrm{z} 150$ and 201, for 3 -MCPD at 147 and 196; quantification was based on the ratio of $\mathrm{m} / \mathrm{z}=201$ and $\mathrm{m} / \mathrm{z}=196$. The limit of detection was $0.03 \mathrm{mg} \mathrm{kg}^{-1}$ oil, and the limit of quantification was $0.1 \mathrm{mg} \mathrm{kg}^{-1}$ oil based on previous validation procedure.

1.3.7. Statistical evaluation of data. All samples were measured twice for all parameters; data are expressed as mean of the measurements. Diagrams, two-way ANOVA (analysis of variance) without replication and paired $t$-test were performed with MS Excel 2016 software.

\section{Results and discussion}

\subsection{Evaluation of the frying oil quality factors}

Free fatty acid (FFA), anisidine value (AV), ultraviolet extinction $\left(\mathrm{E}_{232}\right.$ and $\left.\mathrm{E}_{268}\right)$, and total polar material (TPM) of the oils were determined for monitoring changes of quality during frying circles. These parameters show that several reactions cause the degradation of the oil. The results are expressed as mean of two measurements and are shown in Figure 1 A-E. Twoway ANOVA results are presented in Table 1. Results including the control experiment show 
if there is a difference between the control and the other treatments (salt or fried object), excluding the control samples shows the difference between the treatments.
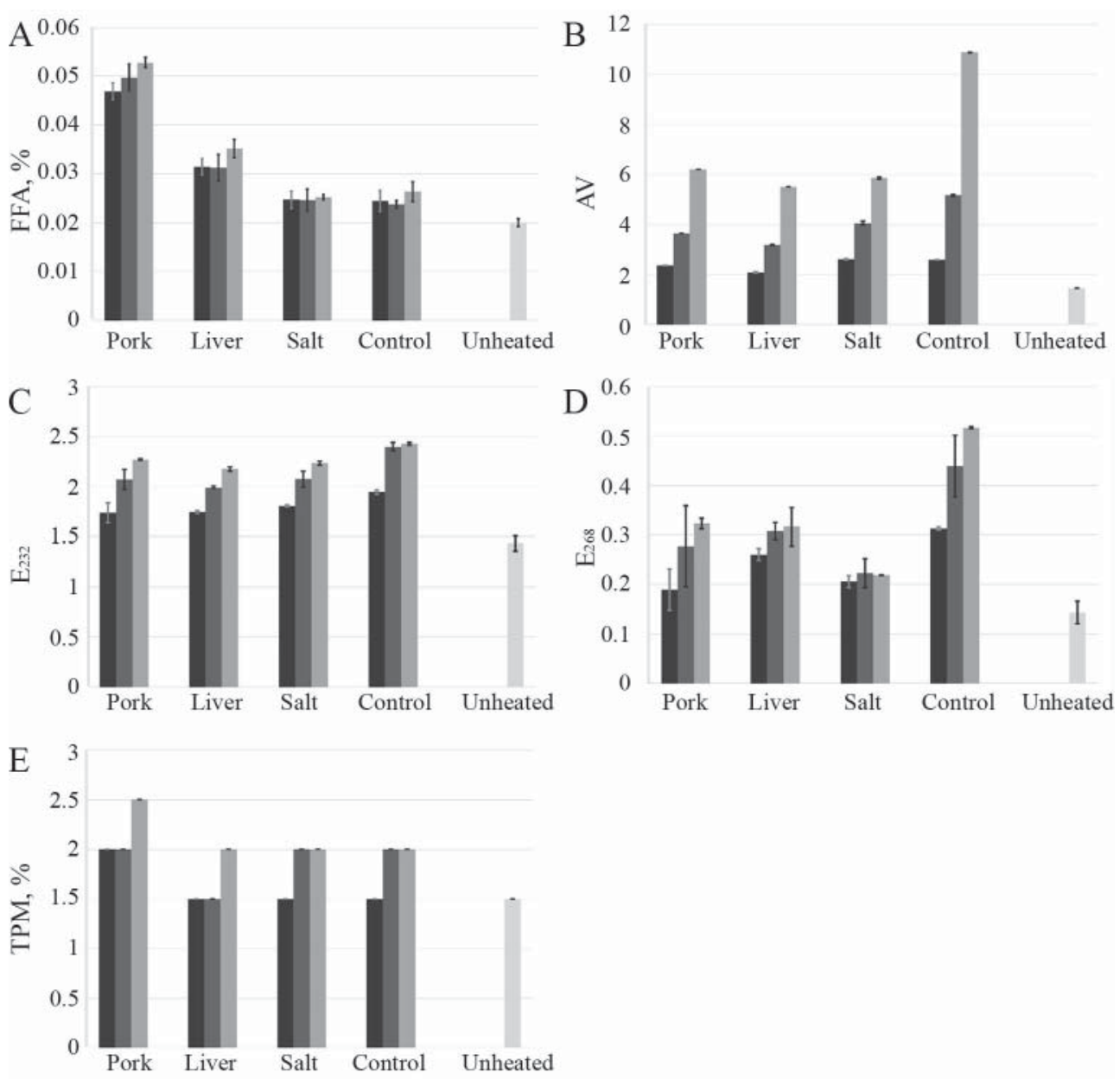

Fig. 1. Changes of quality factors during the experiments. A: free fatty acid (FFA); B: anisidine value (AV); C: UV extinction at $232 \mathrm{~nm}\left(\mathrm{E}_{232}\right)$; D: UV extinction at $268 \mathrm{~nm}\left(\mathrm{E}_{266}\right) ; \mathrm{E}$ : total polar material (TPM)

Table 1. Significance of differences between groups based on two-way ANOVA

\begin{tabular}{lcccc}
\hline & \multicolumn{2}{c}{ Including control experiment } & \multicolumn{2}{c}{ Without control experiment } \\
& Frying circle & Types of experiment & Frying circle & Types of experiment \\
\hline FFA & $*$ & $* * *$ & ns. & $* * *$ \\
$\mathrm{AV}$ & $* *$ & $\mathrm{~ns}$ & $* * *$ & ns. \\
$\mathrm{E}_{232}$ & $* * *$ & $* *$ & $* * *$ & $\mathrm{~ns}$. \\
$\mathrm{E}_{268}$ & $*$ & $* *$ & $\mathrm{~ns}$ & $\mathrm{~ns}$. \\
$\mathrm{TPM}$ & $*$ & $\mathrm{~ns}$ & $*$ & $*$ \\
$3-\mathrm{MCPD}$ & $\mathrm{ns}$ & $*$ & $*$ & $\mathrm{~ns}$. \\
\hline
\end{tabular}

ns: not significant; *: $\mathrm{P}<0.05 ; * *: \mathrm{P}<0.01 ; * * *: \mathrm{P}<0.001$

Acta Alimentaria 49, 2020 
Free fatty acids are formed during the hydrolysis of triacylglycerols promoted by heat or other catalysts. Hydrolysis takes place readily in the presence of heat and water (ZHANG et al., 2012), which is proved by our results, as well (Table 1). The FFA was significantly higher when pork or liver was fried in oil compared to the salty or control experiments. However, when only three circles of frying were conducted, the FFA was low $(<0.05 \%)$ in all samples.

AV represents secondary oxidation products, and it is sensitive especially to unsaturated volatile aldehydes (YANG \& BoyLE, 2016). The highest value was received in the control experiment (10.88), and it was lower in the experiments with pork or liver. This phenomenon can be explained by the distillation effect of the evaporating and bubbling water, therefore, the concentration of dissolved oxygen in the oil decreases and the volatile oxidised products are stripped from the oil (RomANo et al., 2013). The AV values showed significant differences between the frying circles (Table 1).

$\mathrm{E}_{232}$ and $\mathrm{E}_{268}$ indicate the presence of conjugated dienes and trienes, respectively, which are generated by rearrangement of double bonds during deterioration of the oil (YANG \& BOYLE, 2016). Both $\mathrm{E}_{232}$ and $\mathrm{E}_{268}$ increased with progress of frying time, which is in agreement with previous results (WONG et al., 2017a). Including all experiments, the differences between the groups are significant by both factors (frying circles and type of experiments) as shown in Table 1. Excluding the control experiment, there were no significant differences between the other experiments.

Due to the short frying time, the TPM showed low values, with a maximum value of $2.5 \%$. Nevertheless, without the control experiment, the differences were significant between the groups by both factors (frying circle and types of experiment) as shown in Table 1.

\subsection{Evaluation of 3-MCPD content of the frying oils}

The results of 3-MCPD-FE content are shown in Figure 2. The 3-MCPD-FE content of the initial unheated HOSO and the samples of control experiment did not reach the limit of quantification ( $\mathrm{LOQ}=0.1 \mathrm{mg} \mathrm{kg}^{-1}$ ). The highest value for 3-MCPD-FE was reached after the third frying circle by the pork experiment $\left(0.52 \mathrm{mg} \mathrm{kg}^{-1}\right)$. According to the label of package of pork slices, the sodium chloride content of the pork was $1.7 \mathrm{~g} / 100 \mathrm{~g}$, while the chicken liver contained $0.6 \mathrm{~g} / 100 \mathrm{~g}$ salt. Recalculating for the oil, about $113.3 \mathrm{mg} \mathrm{NaCl} / 100 \mathrm{~g}$ oil and $40 \mathrm{mg} \mathrm{NaCl} / 100 \mathrm{~g}$ oil was present during the frying experiment with pork or chicken liver, respectively, while the salty experiment was conducted with $1.0 \mathrm{~g} \mathrm{NaCl} / 100 \mathrm{~g}$ oil. Our results proved that the presence of $\mathrm{NaCl}$ in itself is not enough for the formation of 3-MCPD-FE (Table 2), the same was concluded by ZHANG and co-workers (2015). Therefore, the matrices of the fried object promote the formation reaction. However, comparing the data of pork and liver experiments with paired $t$-test, no statistical difference was found $(\mathrm{P}=0.29)$. The lack of difference in 3-MCPD-FE formation between beef and pork meat was noticed by INAGAKI and co-workers (2019) during heat treatments of meat patties, nevertheless, adding $\mathrm{NaCl}$ to the meat increased the 3-MCPD-FE level in both cases. 


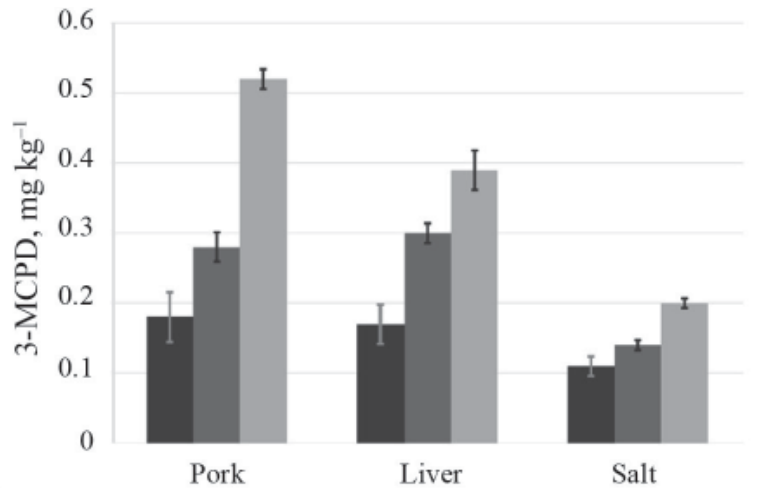

Fig. 2. Change of 3-MCPD-FE content during the experiments. The unheated sample and the control samples were under the limit of quantification $\left(<0.1 \mathrm{mg} \mathrm{kg}^{-1}\right)$.

Table 2. Results of two-tailed, paired t-tests for 3-MCPD content

\begin{tabular}{|c|c|c|c|c|}
\hline & Control & Salt & Pork & Liver \\
\hline Control & & $*$ & * & $* *$ \\
\hline Salt & & & * & $* *$ \\
\hline Pork & & & & ns. \\
\hline Liver & & & & \\
\hline
\end{tabular}

ns: not significant; *: $\mathrm{P}<0.05 ; * *: \mathrm{P}<0.01$

\subsection{Risk assessment for 3-MCPD intake}

The current Tolerable Daily Intake (TDI) defined by EFSA (European Food Safety Authority) is $2 \mu \mathrm{g} / \mathrm{kg}$ body weight/day (EFSA, 2018). In contrast, the Provisional Maximum Tolerable Daily Intake (PMTDI) determined by the Joint FAO/WHO Expert Committee on Food Additives (JECFA) is $4 \mu \mathrm{g} / \mathrm{kg}$ body weight/day since 2017 (JECFA, 2017). Although 3-MCPD occurs in ester bound with fatty acids, it was proved before that 3-MCPD is released during digestion by enzymatic hydrolysis from their esters (ABRAHAM et al., 2013). The oil uptake of the fried object depends on several factors, resulting different fat content of the fried food varying 6-40\% (Velasco et al., 2009). Lower oil uptake is typical for breaded meat products and higher for potato products (SAGUY \& DANA, 2003). Calculating with a mean value (18\%) of oil uptake for breaded pork or chicken liver, after the third frying circle $100 \mathrm{~g}$ of fried product contains 9.36 or $7.02 \mu \mathrm{g} 3-\mathrm{MCPD}$, respectively. These results suggest a low risk to human health, since for an adult with $72 \mathrm{~kg}$ body weight, which is the adult body weight recommended for use in risk assessments (GEPHART et al., 1994), the tolerable daily intake is $144 \mu \mathrm{g}$ based on the current TDI value by EFSA. Taking into account 3-MCPD exposure only through intake of fried pork chop or chicken liver, 1.5 or $2.0 \mathrm{~kg}$ of them can be consumed, respectively. With a balanced and complex diet, the tolerable value is hard to be exceeded, though a potential health concern may emerge in special cases of fried food consumers. 


\section{Conclusions}

The formation of 3-MCPD-FE during deep-fat frying under laboratory circumstances is reported in the present study. The changes of the common quality factors during the short term experiments showed only slight deterioration of the frying oil. However, the differences between the types of experiments and frying circles were significant in most cases. The 3-MCPD-FE formation was affected by the type of experiment; significantly higher 3-MCPDFE content was reached when pre-fried deep frozen food was fried in the oil, though there was no significant difference between the pork and chicken liver results. These results may stimulate further studies on the relationship of frying and 3-MCPD-FE formation by investigating other types of food with different salt content, as well. The preliminary estimation of 3-MCPD-FE exposure calculated from our data suggests a low risk for human health, but this estimation does not take into consideration other factors of human diet.

Funding for this research was provided by the Doctoral School of Food Sciences at Szent István University (Budapest). The Project is supported by the European Union and co-financed by the European Social Fund (grant agreement no. EFOP-3.6.3-VEKOP-16-2017-00005).

\section{References}

Abraham, K., Appel, K.E., Berger-Preiss, E., Apel, E., Gerling, S., .. \& Lampen, A. (2013): Relative oral bioavailability of 3-MCPD from 3-MCPD fatty acid esters in rats. Arch. Toxicol., 87, 649-659.

AOCS (2013): 2- and 3-MCPD fatty acid esters and glycidol fatty acid esters in edible oils and fats by alkaline transesterification and GC/MS. Official Method Cd 29b-13 (Revised 2017).

Calta, P., Velíšek, J., Doležal, M., Hasnip, S., Crews, C. \& Réblová, Z. (2004): Formation of 3-chloropropane1,2-diol in systems simulating processed foods. Eur. Food Res. Technol., 218(6), 501-506.

Choe, E. \& Min, D.B. (2007): Chemistry of deep-fat frying oils. J. Food Sci., 72(5), R77-R86.

De Kock, J., Papastergiadis, A. \& De Greyt, W. (2016): Technological solutions and developments in edible oil processing to minimize contaminants in various oils and fats. $5^{\text {th }}$ Leipzig Symposium 'Processing and Analytics: How does co-operation work in practice' 9-10 March 2016. Leipzig, Germany.

Destaillats, F., Craft, B.D., SAndoz, L. \& Nagy, K. (2012): Formation mechanisms of monochloropropanediol (MCPD) fatty acid diesters in refined palm (Elaeis guineensis) oil and related fractions. Food Addit. Contam. A, 29(1), 29-37.

EFSA (2018): Update of the risk assessment on 3-monochloropropanediol and its fatty acid esters. EFSA Journal, $16,5083$.

Gephart, L.A., Tell, J.G. \& Triemer, L.R. (1994): Exposure factors manual. J. Soil Contam., 3(1), 47-117.

IARC (2013): Some chemicals present in industrial and consumer products, food and drinking-water (Vol. 101). International Agency for Research on Cancer, France, pp. 349-374. ISBN: 9789283213246

InAGaki, R., Ito, F., Shimamura, Y. \& Masuda, S. (2019): Effect of chloride on the formation of 3-monochloro-1,2propanediol fatty acid diesters and glycidol fatty acid esters in fish, meats and acylglycerols during heating. Food Addit. Contam. A, 36(2), 236-243.

ISO (1996): Animal and vegetable fats and oils — Determination of acid value and acidity. ISO 660:1996

ISO (2002): Animal and vegetable fats and oils - Determination of ultraviolet absorbance expressed as specific UV extinction. ISO 3656:2002

ISO (2016): Animal and vegetable fats and oils — Determination of anisidine value. ISO 6885:2016

JECFA (2017): Evaluation of certain food additives and contaminants: Eighty-third report of the Joint FAO/WHO Expert Committee on Food Additives. World Health Organization, Switzerland, pp. 90-106.

Oke, E.K., Idowu, M.A., Sobukola, O.P., Adeyeye, S.A.O. \& Akinsola, A.O. (2018): Frying of food: A critical review. J. Culinary Sci. Tech., 16(2), 107-127. 
Romano, R., Giordano, A., Le Grottaglie, L., Manzo, N., Paduano, A., ... \& Santin, A. (2013): Volatile compounds in intermittent frying by gas chromatography and nuclear magnetic resonance. Eur. J. Lipid Sci. Tech., 115, 764-773.

SAGUY, I.S. \& DANA, D. (2003): Integrated approach to deep fat frying: engineering, nutrition, health and consumer aspects. J. Food Eng., 56, 143-152.

Velasco, J., Marmesat, S. \& Dobarganes, M.C. (2009): Chemistry of frying. -in: Sahin, S. \& Sumnu, S.G. (Eds) Advances in deep-fat frying of foods. CRC Press, Boca Raton, Florida. pp. 33-56.

Wong, Y.H., Lai, O.M., Abas, F., Nyam, K.L., Nehdi, I.A., Muhamad, H. \& Tan, C.P. (2017a): Factors impacting the formation of 3-MCPD esters and glycidyl esters during deep fat frying of chicken breast meat. J. Am. Oil Chem. Soc., 94(6), 759-765.

Wong, Y.H., Muhamad, H., Abas, F., LaI, O.M., Nyam, K L. \& Tan, C.P. (2017b): Effects of temperature and $\mathrm{NaCl}$ on the formation of 3-MCPD esters and glycidyl esters in refined, bleached and deodorized palm olein during deep-fat frying of potato chips. Food Chem., 219, 126-130.

YANG, X. \& Boyle, R.A. (2016): Sensory evaluation of oils/fats and oil/fat-based foods. -in: Hu, M. \& JACOBSEN, C. (Eds) Oxidative stability and shelf life of foods containing oils and fats. AOCS Press, pp. 157-185.

Zhang, Q., Saleh, A.S.M, Chen, J. \& Shen, Q. (2012): Chemical alterations taken place during deep-fat frying based on certain reaction products: A review. Chem. Phys. Lipids, 165, 662-681.

Zhang, Z., GAO, B., Zhang, X., JiAng, Y., XU, X. \& YU, L.L. (2015): Formation of 3-monochloro-1,2-propanediol (3-MCPD) di- and monoesters from tristearoylglycerol (TSG) and the potential catalytic effect of $\mathrm{Fe}^{2+}$ and $\mathrm{Fe}^{3+}$. J. Agr. Food Chem., 63, 1839-1848.

Zhou, H., JIN, Q., WANG, X. \& XU, X. (2014): Effects of temperature and water content on the formation of 3-chloropropane-1,2-diol fatty acid esters in palm oil under conditions simulating deep fat frying. Eur. Food Res. Tech., 238, 495-501.

Ziailfar, A.M., Achir, N., Courtois, F., Trezzani, I. \& Trystram, G. (2008): Review of mechanisms, conditions, and factors involved in the oil uptake phenomenon during the deep-fat frying process. Int. J. Food Sci. Tech., 43, 1410-1423.

Open Access statement. This is an open-access article distributed under the terms of the Creative Commons Attribution 4.0 International License (https://creativecommons.org/licenses/by/4.0/), which permits unrestricted use, distribution, and reproduction in any medium, provided the original author and source are credited, a link to the $\mathrm{CC}$ License is provided, and changes - if any - are indicated. (SID_1) 